\title{
Causes of Rail Staff Fatigue: Results of Qualitative Analysis and A Diary Study
}

\author{
Jialin Fan ${ }^{10000-0003-1530-4739]}$ and Andrew P. Smith ${ }^{20000-0001-8805-8028],}$ \\ ${ }^{1}$ School of Psychology, Shenzhen University, L3-1236, South Campus, 3688 Nanshan Road, \\ Shenzhen, 518000, China \\ FanJL@szu.edu.cn \\ ${ }^{2}$ Centre for Occupational and Health Psychology, School of Psychology, Cardiff University. \\ 63 Park Place, Cardiff, CF10 3AS, United Kingdom \\ SmithAP@ cardiff.ac.uk
}

\begin{abstract}
The purpose of this study was to investigate the causes of fatigue among rail staff by analysing qualitative data and conducting an online diary study. It had a closer look at the experience of fatigue among rail staff and brought a more detailed blueprint picture of fatigue and its causes in the rail staff's real-life. Study 1 analysed 133 responses of qualitative data from rail staff, and Study 2 was a diary study examining fatigue and its related risk factors before and after work, on the first and the last day of a working week in 19 rail staff. The findings from the two studies, using different methodologies, showed similar results that fatigue was a result of heavy workload, long working hours, shift-work, and insufficient rest and sleep. Fatigue before work mainly resulted from sleep quality, length of sleep, and the time spent on commute, while fatigue after work resulted from the workload and shift type. Evidence has demonstrated that overtime work, specific shift patterns, insufficient rest days between opposed shifts, and poor timing of breaks during work were also associated with fatigue.
\end{abstract}

Keywords: Workload, occupational fatigue, rail staff, qualitative analysis, diary study

\section{Introduction}

Occupational fatigue is a daily experience among working people. It is also a wellestablished occupational hazard which has been identified as a contributing factor for incident and accident, for injuries and death, in a wide range of occupational settings (e.g., transport, hospital, construction), with implications on cognitive performance. Although the implications for fatigue in transport are well documented, the amount of research in rail fatigue was limited as this field was historically smaller than road and aviation fatigue $[1,2]$. In the railway industry, fatigue is a risk for both train and human safety because the majority of jobs in this industry are safety-critical.

Evidence for fatigue in rail staff has been found in many existing studies. Train drivers and signallers (i.e., railway controller) were the most investigated samples in fatigue studies [3], as fatigue-related human error in these roles could, obviously, 
result in serious safety consequences. However, the other job roles in this industry were also safety-critical, including the conductor, engineer, and even station worker. Although some of these job roles do not involve the train operation, their duties are designed for ensuring the train, the rail track, the passenger, and the station are secured. An engineer, for example, working in the event of emergencies to resolve any faults that might occur in the railway infrastructure, was found to suffer from fatigue problems and the unpredictability of the call-out duties prevented relaxation which then further cumulated in fatigue [4]. A large-scale survey among UK train staff covering all the job roles [5] indicated that issues of fatigue were apparent in any job roles mentioned, even including the station workers who carry out the duties of selling and checking tickets, making sure that passengers get on and off the train safely, and signalling the conductors or driver to depart.

Failure to manage rail staff fatigue would result in serious consequences. In general, the after-effect of fatigue includes impairments in attention, memory, information processing, decision-making, perception, and work performance [6,7], as well as the decreased response of cells, tissues, or organs after excessive stress or activity [8]. It has also been found to have a negative association with mood, wellbeing, physical and mental health, and personal safety [9, 10, 11, 12]. Fatigue and its impact on safety-critical performance increased the risk of human error and was suggested as a key issue in the rail industry [13]. In train accident and incident reports, staff fatigue is considered to be a causal factor [14, 15, 16, 17, 18]. By reviewing 98 rail investigation reports found in the SPARK, an organised library of researches and reports within the international rail community, Fan and Smith [3] found 23 of the reports identified fatigue as one of the contributory causes of the train incident or accident.

Rail staff fatigue is subject to general stressors of occupational fatigue and industry-specific factors. Smith [19] reviewed fatigue in different transport sectors and indicated that that the fatigue problem between sectors is similar, while the features between them are different. He suggested that the scientific approach to defining fatigue should apply to all of these sectors, but a "one size fits all" approach to regulating fatigue may be inappropriate to all. The amount of related fatigue studies in the rail industry, however, is very limited just as Anund et al. suggested [2], and the causes of rail staff fatigue required further studying. Section 1.1 and section 1.2 review literature of the causes of fatigue in general, and in the railway industry. Then, the rationales and objectives of current studies are introduced in Section 1.3.

\subsection{Causes of Occupational Fatigue in General}

In general, the causes of occupational fatigue are varied, including generic causes not specific to the workplace (e.g., duration of the task, sleep loss), and work-related causes (e.g., job demands and control); it is also affected by individual differences and combined effects. Stress is the starting point of fatigue, and long-term stress results in fatigue. Cameron [20] stated that the term fatigue is synonymous with a generalised stress response over time, which suggests that the risk factors of occupational stress will also result in fatigue. The work-related causes of fatigue, therefore, could be the stressor of occupational stress, including work demands, lack 
of control and support, and individual differences. The causes could also be the working environment, shift work and the combined effects of these factors [5, 21].

The most prominent cause of fatigue is the time spent on tasks. Length of time-ontask leads to fatigue and a decrement in cognitive performance. Time-on-task refers to the length of time spent involved in a task. Cameron [20] pointed out that time is probably the most relevant variable which is uniquely associated with fatigue. In the course of prolonged tasks, it generally becomes increasingly difficult to maintain performance, which seems to reflect a cumulative increase in the effort required to deploy cognitive resources. In such cases, performance is impaired and fatigue accumulates over time. The range of studies on the time on task effect involved periods of a few minutes in duration [22] to several weeks of 8-hour days' continuous time [23]. The effect is particularly noticeable in tasks requiring sustained attention, with longer reaction times and/or greater numbers of errors [24]. Gilbertova and Glivicky [25] stated that this effect is amplified by monotony or boredom, while it may be suppressed in more interesting tasks. In addition, breaks (e.g. task switching) and rests provide fatigue recovery from such an effect [26].

Sleep loss is one of the main factors that can lead to fatigue. Many of the fatigue studies involve sleep-related risk factors, including sleep quality, duration, and deprivation [27, 28, 29]. Most people experience the feeling of fatigue after spending one or more nights without sleep. Technically, sleep loss is associated with significant declines in global metabolic activity within the brain, especially the pre-frontal inhibitory and thalamic information-processing system [30]. That is, alertness and attention decrease, and the probability of brief attentional lapses increases. Sleep deprivation also disrupts the normal functioning of the emotional-cognitive integration system, resulting in increased negative emotion [31] and impaired decision-making [32]. Additionally, May and Baldwin [33] noted that active and passive fatigue can impair the performance, either directly through task effects, or indirectly by worsening sleep-related fatigue.

In the workplace, job demands were considered to result in occupational fatigue $[34,35]$. Job demands refer to physical or mental workload, and the effects of some demands that continue beyond the demand itself are known as the after-effects. Although job demands are not necessarily negative, they may turn into stressors if meeting them requires high levels of effort. These stressors are, therefore, costly and are associated with negative responses such as depression, anxiety, and fatigue. Besides, Karasek [36] found that job control (i.e., the personal ability to control work activities) is a major moderator between high job demands and high strain. In the job demands-control model (JDC) he proposed, it is the combination of high job demands and low job control that is associated with high job strain. Results of the studies focusing on job control support its moderating effect on the relationship between high job demands and fatigue [37, 38]. Van Yperen and Hagedoorn [39] stated that as job demands increase, the high job control needed to limit fatigue also increases. In the 1980s, a social support dimension was added to the JDC model, resulting in the job demand-control social (JDCS) model [40]. The new element, social support at work, was defined as the overall levels of helpful social interaction available on the job from co-workers or supervisors [41]. This JDCS model indicated that high job demands combined with low control and low social support results in feelings of isolation and leads to higher levels of fatigue and strain. 
Research on occupational fatigue has also focused on the effects of irregular hours of work (i.e., shiftwork). Humans have important physiological requirements for sleep and a stable biological clock, but in many industries, the jobs of humans are designed to operate on a $24 / 7$ basis. When people lose sleep or have their internal clock disrupted, they usually begin to feel fatigued. Previous studies have identified the start time [42, 43], shift work, and its duration [44], as potential causes of fatigue. Shift work, especially the early morning shift and the night shift, disrupts the sleep-wake cycle [45] and deprives workers of sleep [46], which in turn reduces performance [47]. Shift workers may have little time to recover when working certain shift hours, which makes them more likely to suffer from chronic fatigue. When reviewing the literature on shift systems, Folkard, Lombardi, and Tucker [48] highlighted that the risk of an accident increases over a series of work shifts, especially at night, and also increases as the total shift length increases over 8 hours (in any 24-hour period).

Individual differences play a role in fatigue as well. Many individual factors have been studied, including personality [27, 49], coping type [50], health-related behaviours (e.g., smoking [51]; drinking excessive amounts of alcohol [52, 53]; eating habit [54]), and even clock genes [55]. The important role of individual differences (such as coping styles) on fatigue is indicated in the Demands, Resources, and Individual Effects model (DRIVE model) [56]. DRIVE model is an occupational fatigue model which demonstrates not only the effects of job demands and job resources (support and control), but also the impact of individual differences on work fatigue and health outcomes. Parkes [27, 49] stated that individual differences in personality and coping can play important roles in the processes by which work conditions influence fatigue and health outcomes. Karasek [36] noted that individuals can manage their job demands effectively in a controllable situation. In other words, the effect of job demands somehow depends on how individuals appraise stressors and act in response [35]. As for clock genes (also called clock circadian regulators), although the investigation of polymorphisms in occupational fatigue is in its infancy, some polymorphisms have already been identified, such as diurnal preference, an intrinsic period, responses to sleep deprivation and night shifts $[55,57,58,59]$. Van Dongen and Belenky [60] suggested that the selection of individuals with a specific diurnal preference or those who are relatively little affected by sleep loss or circadian effects for specific tasks (e.g., night shifts or early morning shifts) can help to improve productivity, reduce errors, and decrease incidents and accidents. Although clock genes provide an interesting angle to understand the individual difference in perceived fatigue, the research presented in this paper does not study fatigue at the gene level yet.

\subsection{Causes of fatigue in rail industry}

Just like the workers in any other industries, rail staff are subject to general stressors of occupational fatigue. Other than that, they are also exposed to industry-specific factors which could associate with fatigue, such as sustained vigilance works, shiftwork, and harsh working environments [61, 62]. With systematically reviewing the causes of rail staff fatigue, Fan and Smith [3] summarised that the factors contributing to rail staff fatigue included long working hours, heavy workload, shift work, 
insufficient sleep, poor working environment, as well as individual differences. In 
(i.e., physical, mental, and emotional fatigue)[63], workload plays an important role resulting in fatigue in all its three dimensions. Prolonged work and insufficient rest resulted in physical fatigue, while the poor shift pattern was more related to mental and emotional fatigue [64]. Darwent et al. [65] found that fatigue was generally associated with insufficient sleep obtained before shifts, but there were individual differences in fatigue resistance. Although the environmental factors were found to affect rail staff fatigue [66, 67], such effects seemed to appear in particular job roles. For example, noise and vibration were more influential in train drivers and conductors and associated with their fatigue, while fumes seemed to affect more engineers but were not found to contribute to fatigue [5].

\subsection{Rationale of present research}

Recent research has addressed the topic of work fatigue in the rail industry. Much of this has been concerned with the potential consequence and general causes of fatigue and there has been less research about the detailed causes of fatigue closely to rail staff members' real-life setting. There is limited evidence about cumulated fatigue in this industry and the understanding of the effect of current shift work on fatigue is not enough. Therefore, research is needed to explore the causes of rail staff fatigue in more detail using qualitative data. A diary study is also better for understanding cumulative fatigue. Diary studies have been used with fleet staff (i.e., engineer) in the railway industry [68], whereby fatigue and fatigue-related risk factors were assessed at the start and end of the first and the last day of their working week, with similar reliability and validity to an everyday diary. Considering the real-life setting, a simple measure and an "online" method is required so that the diary can be easily used in the workplace among rail staff. One reason is because an online single-item scale is as reliable as the offline version of it and longer scales [5, 64, 68].The other is because such measures are able to measure fatigue without interrupting or changing staff members' work behaviour.

The main aim of the current research described in this paper is to investigate the causes of rail staff fatigue using two different methods including either qualitative data or a diary. The present research attempts to have a closer look at the fatigue experienced among rail staff and to have a more detailed blueprint picture of fatigue and its causes in the rail staff's real-life. Considering the effect of individual differences that has been mentioned in previous studies, the DRIVE model is used as the research framework in this paper as it has such elements and has been applied to workload and fatigue. The first study described in Section 2 uses qualitative data to investigate the causes of rail staff fatigue. The second study, a diary study, described in Section 3 assesses their fatigue and its risk factors in a real-life setting, at the start and end of the first and last day of a working week. 
insufficient sleep, poor working environment, as well as individual differences. In

\section{Study 1 - Qualitative Data}

\subsection{Methods}

Participant. A total of 133 participants provided the qualitative data in the online survey. The majority of these participants were male $(\mathrm{N}=104,78.2 \%)$, with a mean age of 44.53 years $(\mathrm{SD}=9.773$, minimum $20.5 \mathrm{yr}$, maximum $62.92 \mathrm{yr})$. There were $63.9 \%$ of them who worked in South Wales, UK, while the rest worked in North Wales. The main occupations in the sample were train drivers $(23.3 \%, \mathrm{~N}=31)$, conductors $(21.8 \%, \mathrm{~N}=29)$, administrators $(17.3 \%, \mathrm{~N}=23)$, and engineers $(15.8 \%$, $\mathrm{N}=21)$, followed by managers $(15.0 \%, \mathrm{~N}=20)$ and station workers $(6.0 \%, \mathrm{~N}=8)$. One participant had missing job type data. The School of Psychology Research Ethics Committee at Cardiff University reviewed and approved this online study.

Materials. This study uses qualitative data to investigate the causes of rail staff fatigue. The material used in this study was an online questionnaire investigating causes of rail staff fatigue. This questionnaire contains thirty-eight 10-point questions and one open-ended survey question, "Do you have any comments on your working hours? (e.g. how they could be improved)." The current paper mainly reports the results of the qualitative data of the survey (e.g., the responses of the open-end question), and the quantitative data was report in one of our previous paper [64].

Data analysis was carried out using SPSS 23. The thematic analysis strategy [69] was employed to analyse the qualitative data. The comments were read several times, and the themes listed above were identified and highlighted by coloured pens. Some text involved two or more theme.

\subsection{Results - Thematic Analysis (Opening Question)}

There were 133 responses to this question. The answers to this open-end question, "Do you have any comments on your working hours? (e.g. how they could be improved)", demonstrated that the factor of working hours is not the only risk factor of fatigue. The themes of these responses included job demands/overtime work, length of shift, timing to work, break/rest, flexibility of working pattern, and job support and control. Timing to work was the most popular theme, followed by length of shift, job demands/overtime work, break/rest, and flexibility of working pattern. The frequency of these themes is shown in Fig.1 


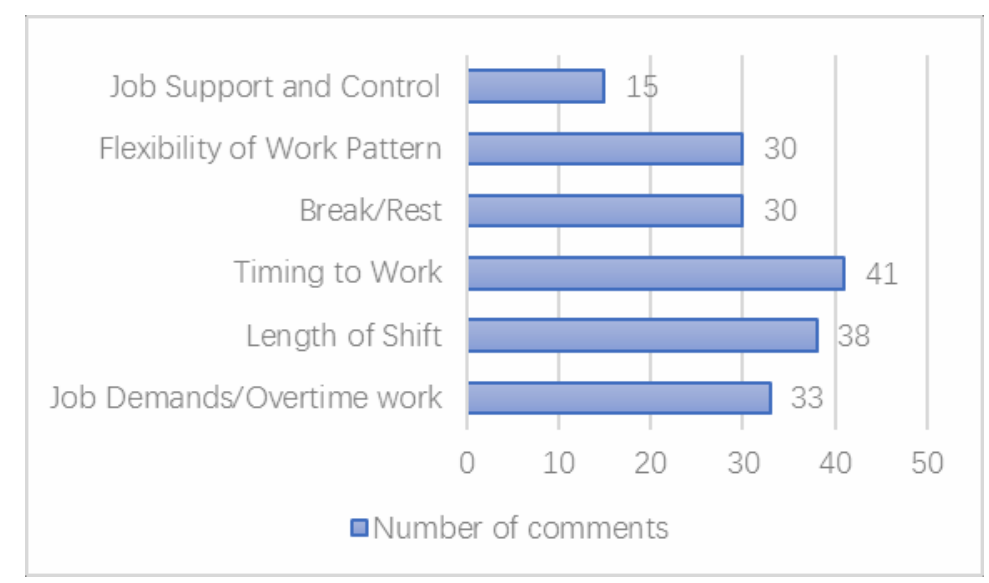

Fig. 1. Number of comments on each theme.

Theme 1. Timing of work. The first topic described was timing of work, the most popular theme being mentioned by 41 comments. Participants generally claimed that less shift-work would decrease the fatigue problem.

Participant 81 (engineer): “...Shift-work and early shift start times affect me with fatigue."

Participant 115 (engineer): "More day working, shorter night shifts."

Participant 90 (train driver): "If the shifts were better balanced instead of booking on at 03.27 in the morning and working through on night shift, I feel this would help."

Participants described how the irregular hours of shift-work affected their work-life balance, and how difficult it was to recover from a series of night shifts when an early morning shift was scheduled immediately after.

Participant 94 (administrator): "Too many late shifts, too many weekends, have no enough family time. Work/life balance heavily depends on work and changes on shifts always make things worse never better."

Participant 28 (conductor): "Spare shift which can be moved three hrs either way and it only advised 48hrs before, messing up the healthy lifestyle, sleep and society activities. This should be reduced to an hour."

Participant 69 (manager): "We have to work during the nights. Sometimes working from the day shift on the previous day, then back to a morning start after minimal rest, which can be tiring."

Participant 107 (conductor): "Poor rostering is the main issue. One issue is finishing at 02.30 Sunday morning. Having Sunday off then in 03.43 starts Monday morning. How am I supposed to prepare my body for that?"

Participants believed that having a more consistent time to work would reduce fatigue, especially within the same working week. A varied and too changeable start time resulted in their fatigue. 
Participant 19 (train driver): "I try to regulate my shift pattern by having a permanent swap with one of my colleagues so that I always do early shifts and he always does late shifts. I find that the change back and forth between early and late (shifts) is the largest contributory factor that influences my fatigue."

Participant 109 (conductor): "A similar start time all week would help enormously, e.g. if on earlies shifts starting around the same time all day, and not varying between 03.43-07.01 like one week in my link currently does."

This participant mentioned that personal preference of time of day could help with coping with specific shift-work.

Participant 25 (train driver): "I try to swap for the late turns as I find they suit me better. On early shift, I would say that I lose about a night sleep over the four shifts. I generally struggle to get to sleep early, even when I'm tired, though I do manage to get up OK."

Theme 2. Length of Shift. The second theme highlighted the length of shift-work that the train crew took which was mentioned by 38 comments. Participants reported that current working hours were too long, that the length of each turn should be limited, and that the number of maximum working hours should be reduced.

Participant 9 (conductor): "(Working hours) could bring in a maximum 9.5-hour day with having a maximum of 4 hours on a train at any given time."

Participant 76 (engineer): "Working hour should less 12 hours and average 10hour shifts throughout the month."

Participant 111 (engineer): "I think 10 hours should be maximum shift length when working on safety critical work."

Participants also suggested a reduction in the length of early morning and night shifts.

Participant 75 (train driver): "The jobs that start very early in the morning (before 6am) should not be allowed to be much longer than 6-7 hours long in turn length."

Participant 87 (engineer): "Reduce 12 hours to 10 hours or even 8 hours, especially on nights."

Theme 3. Job Demands/Overtime Work. The third theme described the demands that were placed on the train crew and the overtime work that they take. With regards to job demands, participants described how the job demands were high.

Participant 40 (administrator): "It's not the length of shifts that make me feel fatigued, but the constant questions, and the concentration needed to check tickets, make sure that people don't get stuck in the ticket barriers etc."

Participant 85 (train driver): "The commitment to covering on-call requirements and being called out in addition to normal daily hours, massively impinges on my fatigue and well-being."

Participant 105 (train driver): “... the problem comes with the intensity of work within the turn."

More specifically, participants reported that the nature of their work can be mentally or emotionally demanding and that their fatigue is often more emotional or mental. 
over the same route multiple times, e.g. City line - mentally exhausting."

Participant 128 (manager): "I have a mentally challenging job."

Participant 63 (station worker): “...it's more emotional and mental fatigue that affect how I feel after a working day."

Overtime work was frequently mentioned, and participants described how their overtime work had high demands.

Participant 84 (manager): "I work 12 hrs shift. Every shift I work overtime for approximately 40 minutes (20 minutes at the start and 20 minutes after the shift finishes) to allow for a shift handover."

Participant 50 (manager): "The overtime mentioned is event working. It is expected in some departments that staff who volunteer for events complete their full shift before volunteering to work an event for payment. This can lead to staff working in excess of 12 hours. A member of the resources team recently worked a 15-hour shift; this is dangerous given that staff are managing large crowds and have to make safety decisions, which is difficult to do when tired. When finishing evening events, staff can finish as late as 01.30 but are expected to return to work for their normal shifts with very little rest."

Participant 84 (manager): "The commitment to covering on-call requirements and being called out in addition to normal daily hours, which massively impinges on my fatigue and well-being."

Participants specifically pointed out that the reason for their high job demands and overtime work was insufficient staffing.

Participant 68 (conductor): "There are not enough people to complete all the tasks that need completing. Many people within the function are doing two jobs and working in the evenings/weekends."

Participant 56 (manager): "Roster has insufficient staff for the number of hours required (i.e., the roster should have 7 to cover properly but only has 5).

Overtime unavoidable at times as job mandatory to cover."

Participant 106 (administrator): "... the biggest issue is the amount of time we spend single manned (i.e. on our own with no backup or support at the station). This has increased in recent months due to staff cuts."

Theme 4. Break/Rest. The fourth theme described was breaks during work and rest after work. Insufficient rest and break were reported to lead to fatigue, as well as increase risks to the safety.

Participant 105 (train driver): “...the breaks are too infrequent and often too short. Too much time spent without a break leading to fatigue."

Participant 122 (train driver): "Breaks are very tight, and if we are late, we feel under pressure to take subsequent trains on time... (Break) sometimes was split into two rushed breaks. This means it is very difficult to eat a hot meal or to shut off for 5 mins, which is not great in a safety critical environment."

Participants mainly complained that the timing of rest during the shift was poorly placed, either too early or too late, and needed to be more thoughtful.

Participant 8 (conductor): "The breaks are in the wrong place. Right at the start or right at the end." 
Participant 74 (train driver): "Repetition of work, i.e. 4 hours of constant driving

Participant 10 (conductor): "...Could we please have breaks in the middle of a shift and not after 30 minutes of starting a ten-hour shift or at the end of one?"

Participants also suggested to have more rest days and to arrange them more strategically, especially between opposing shifts.

Participant 37 (administrator): "More recovery time. More occasions of consecutive rest days (1 occasion every six weeks at present)."

Participant 54 (train driver): "More rest between opposing shifts. Sometimes there is only 26 hours between late afternoons and early mornings."

Theme 5. Flexibility of Working Pattern. Flexibility of working pattern was frequently mentioned in the comments. Participants described how a flexible working pattern could benefit their work-life balance and suggested to increase flexibility of working time and working place.

Participant 5 (administrator): "Flexible working would assist people to manage their day and improve work-life balance. For example, you can choose to come in at 7 knowing that you can leave at 3 and enjoy time with family or enjoy sunshine etc. Also, you can accrue flexible days."

Participant 86 (manager): "More flexible approach to start and finish times. I.e., if you work over one day, you should be able to finish early the next day for example. Come in later and go home later on some days or the other way around and more working from home where the job allows."

Theme 6. Job Support and Control. Participants reported low levels of job support and control, mainly including lack of support from the manager or other colleagues and unfair arrangement of working time due to their younger age.

Participant 18 (manager): "There is little concern from management or unions about the amount of work and length of turn for jobs starting during the late night. The reality of these shifts regardless of attempts to manage those means that almost all drivers working these shifts experience moments and incidents of micro-sleeps and concentration loss during them."

Participant 36 (train driver): "I am in the bottom link (rota) in work as I'm junior. We have ALL the very early starts and ALL the late starts. As you progress (10 years roughly), you move up the links and get easier start times. This should be spread out fairly and not left to the same 35 men."

\subsection{Summary}

This study used qualitative data to investigate the causes of rail staff fatigue. The themes of the responses included job demands/overtime work, length of shift, timing to work, break/rest, flexibility of working pattern, and job support and control. In which, participants mainly reported that irregular timing of work and impaired worklife balance led to fatigue and that recovering from opposed shifts was extremely difficult. Participants also reported high job demands, especially mental and emotional demands, overtime work, and long length of shift-work. The amount of rest and break were reported as insufficient, while it was suggested that the timing of 
breaks during work could be better arranged. A flexible work pattern was believed to improve work-life balance. Participants also raised concerns about the lack of job support and control. These comments provided important insights into the nature of jobs in the railway industry and inspired the following diary study, described in Section 3.

\section{Study 2 - A Diary Study}

\subsection{Overview (Links between study $1 \& 2$ )}

Study 1 showed that workload, overtime prolonged shift work, insufficient rest during work, and poorly arranged shift patterns were reported to be the essential causes of fatigue among rail staff. A diary study was the next logical step in this research in order to closely assess the rail staff's shift patterns and daily work lives. It would be useful to investigate occupational fatigue as it provided a record of subjective feelings and work experiences related to fatigue in context.

The present study is a diary study where individuals were required to record their fatigue before and after work, rest and breaks, their workload, and their shift pattern within one working week. The goal of this study was to demonstrate a relationship between fatigue workload, working hours and explore other risk factors mentioned in Study 1 described in Section 2, such as shift pattern, overtime work, sleep quality, and breaks during work. The experimental hypothesis for this study predicted that high workload, long working time, irregular shift time, and insufficient breaks will increase fatigue. Reported fatigue will be higher at the end of a workday and at the end of workweek due to the effect of workload. 


\subsection{Methods}

Participant. Participants were recruited from volunteers from a train company in the UK $(\mathrm{N}=19$, mean $( \pm \mathrm{SD})$ age $=41.86 \pm 9.89 \mathrm{yr}$.; $74 \%$ male $)$. The main job types reported were managers, conductors, drivers, station workers, engineers and administrators.

Materials. The diary consisted of 15 questions (shown in Table 1), including six questions to be answered before work and nine questions to be answered after work. It was designed based on the material used in Smith and Smith's [68] diary studies. The diary was completed immediately before starting work and immediately after finishing work on the first and the last day of a working week (4 days). The questions in the pre-work diary covered sleep duration and quality, time taken to travel to work, fatigue due to the commute, general health status, and alertness before starting work. The questions in the post-work diary recorded workload, effort, fatigue, stress, break duration, work duration, the time they finished work, and level of distraction during work. There were extra questions in the post-work diary on the last day which asked whether participants worked the same time every workday in the working week.

Table 1. Questions in the Diary.

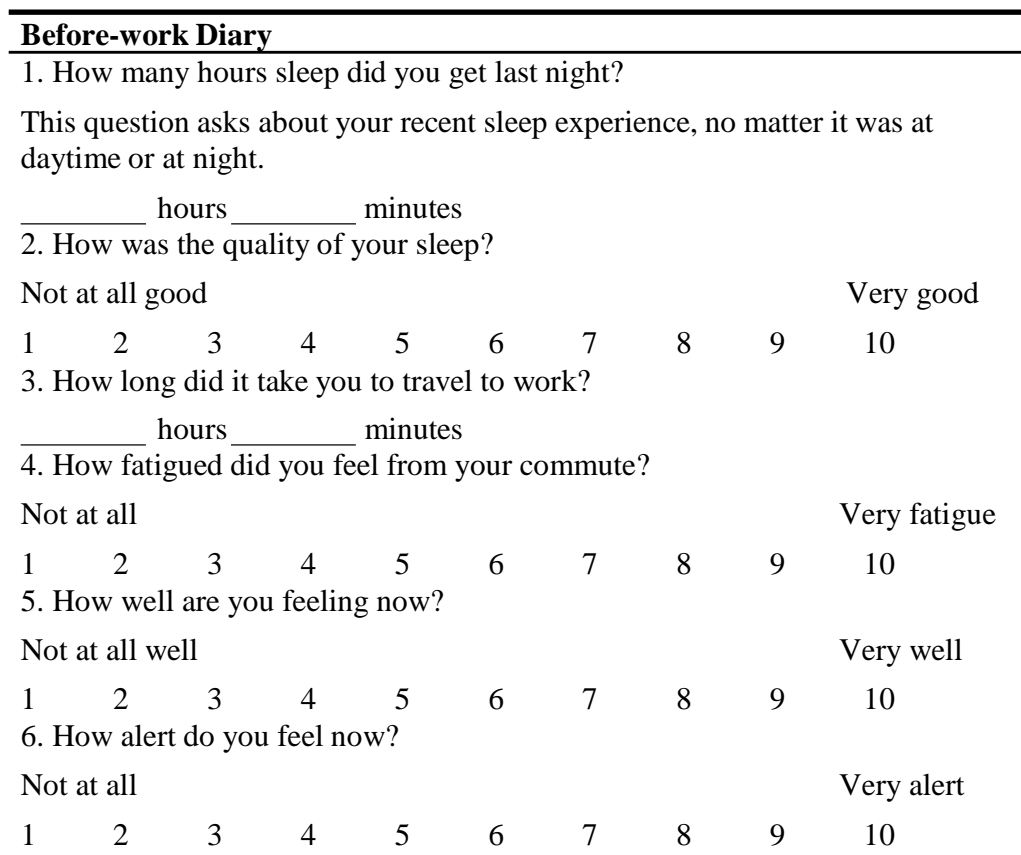




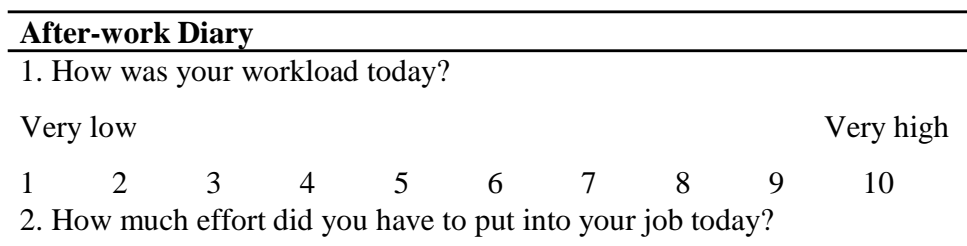

Very little

A great deal

$\begin{array}{llllllllll}1 & 2 & 3 & 4 & 5 & 6 & 7 & 8 & 9 & 10\end{array}$

3. How fatigued do you feel now?

Not at all

Very fatigue

$\begin{array}{llllllllll}1 & 2 & 3 & 4 & 5 & 6 & 7 & 8 & 9\end{array}$

10

4. How stressed do you feel now?

Not at all

Very stressed

$\begin{array}{llllllllll}1 & 2 & 3 & 4 & 5 & 6 & 7 & 8 & 9 & 10\end{array}$

5 . What was the total length of your breaks today?

hours_ minutes

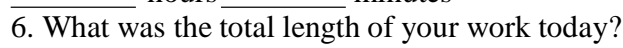

hours minutes

6.1. What time did you start work today? (e.g. Hour: 23 Minute: 30) hours minutes

$\overline{6.2 . ~ W h a t ~ t i m e ~ d i d ~ y o u ~ f i n i s h ~ w o r k ~ t o d a y ? ~}$

hours_ minutes

$\overline{7 .}$ During your work today, to what extent were you thinking about other things rather than work?

Not at all

Very much so

$\begin{array}{llllllllll}1 & 2 & 3 & 4 & 5 & 6 & 7 & 8 & 9 & 10\end{array}$

$8^{*}$. Did you work at the same time on other days of this week? (start time, end time, and length)

Yes

No

$8.1 *$ If no, which day(s) did you work at a different time? And what was the total length of your work on that day(s)? (hours, minutes)

8.2* What time did you start and finish work on each of those days? For example, Day $2-6.30 \mathrm{am}$

* The question only asked in the after-work diary on the last day. 
Procedure. An invitation e-mail attached with information about the study and an informed consent form was sent to potential participants. After participants signed and returned the forms, they were asked to provide the start date of their next working week. Then, the introduction of the diary and the links of the four test sections were sent to them. On the testing day(s), participants were asked to complete the online diary immediately before starting work and immediately after finishing work via a computer or mobile phone. Subjects were free to withdraw from the survey at any point. This study was reviewed and approved by the School of Psychology Research Ethics Committee at Cardiff University.

Analysis. Data analysis was carried out using SPSS 23. Data were analysed using a variety of tests, including Pearson correlation (one-tailed) and one-way ANOVA. The variables tested included subjective fatigue, workload, length of sleep, quality of sleep, time taken to travel to work, alertness, effort, stress, working hours, length of breaks, level of distraction, and time starting work (e.g., shift type).

\subsection{Results}

Descriptive. Overall, 19 participants fully completed the diary and $73.7 \%$ of them were male. The most common job types reported were managers $(26.3 \%)$, followed by train drivers, conductors, engineers, station workers (all 15.8\%), and administrators $(10.5 \%) .31 .6 \%$ of participants did night shifts or early morning shifts, while others did daytime shifts. During the testing week (4 working days), $43.1 \%$ of participants worked two or more different shift times. Table 2 below shows the difference in fatigue and other variables between the first and last workdays. As is shown, self-reported fatigue increased after work and over the workweek. Quality of sleep and alertness decreased during the week while work stress increased.

The variable of time starting work was classified in to four shift type groups, including 1) the morning shift starting from 7:00 to $12: 59,2$ ) the afternoon shift starting from 13:00 to 18:59, 3) the night shift starting from 19:00 to 00:59, and 4) the early morning shift starting from 1:00 to $6: 59$. In the first day, $47.4 \%$ of participant worked the morning shift, $15.8 \%$ of them worked the night shift, and $15.8 \%$ of them worked the early morning shift. In the last day, participants working morning shifts decreased to $36.8 \%$, participants working night shifts slightly decreased to $10.5 \%$, and those who worked early morning shifts slightly increased to $21.1 \%$. The maximum working hours in both days was 12 hours, and $21.1 \%$ of participants worked over 10 hours every day during the week, this was mainly reported by engineers and drivers. The minimum working hours was 5.5 hours on the first day and 5.75 hours on the last day, reported from a station worker. 
Table 2. Descriptive Statistics for Mean of Variables.

\begin{tabular}{|c|c|c|c|c|c|}
\hline & \multirow[t]{2}{*}{ Variables } & \multicolumn{2}{|c|}{ First Day } & \multicolumn{2}{|c|}{ Last Day } \\
\hline & & Mean & S.D & Mean & S.D \\
\hline \multirow[t]{6}{*}{ Before Work } & Length of Sleep (hour) & 7.18 & 1.37 & 7.08 & 1.31 \\
\hline & Quality of Sleep & 6.05 & 2.12 & 5.84 & 2.65 \\
\hline & $\begin{array}{l}\text { Time Taken to Travel to Work } \\
\text { (hour) }\end{array}$ & 0.50 & 0.37 & 0.44 & 0.26 \\
\hline & Fatigue before Work & 2.16 & 1.21 & 2.47 & 1.61 \\
\hline & $\begin{array}{l}\text { General Health Status (i.e., } \\
\text { feeling well) }\end{array}$ & 7.47 & 1.50 & 6.58 & 2.12 \\
\hline & Alertness & 7.11 & 1.52 & 6.58 & 2.34 \\
\hline \multirow[t]{7}{*}{ After Work } & Subjective Workload & 5.79 & 2.18 & 5.42 & 2.43 \\
\hline & Effort & 7.16 & 2.01 & 6.37 & 2.63 \\
\hline & Fatigue after Work & 6.42 & 2.12 & 7.11 & 2.00 \\
\hline & Stress & 3.79 & 2.30 & 4.58 & 2.09 \\
\hline & Length of Breaks (hour) & 0.90 & 0.69 & 0.87 & 0.51 \\
\hline & Working Hours (hour) & 8.48 & 1.65 & 8.75 & 1.63 \\
\hline & Distraction during Work & 5.11 & 2.58 & 5.32 & 2.65 \\
\hline
\end{tabular}

Analysis in Each Diary Session. A one-tailed Pearson correlation was run to investigate the association between fatigue and other risk factors in each diary. There were four diary sessions, before and after work on the first and last days of the work week.

In session 1, the first day before the work session, fatigue before work was associated with time spent travelling to work $(\mathrm{r}(19)=.752, \mathrm{p}<.01)$, with more time spent on the commute being associated with higher fatigue ratings. Fatigue was also negatively correlated with general health status $(\mathrm{r}(19)=-.469, \mathrm{p}<.05)$, and alertness $(\mathrm{r}(19)=-.430, \mathrm{p}<.05)$ at a significant level. High sleep quality was significantly associated with longer length of sleep $(\mathrm{r}(19)=.428)$, better general health status $(\mathrm{r}$ $(19)=.601)$, and more alertness $(\mathrm{r}(19)=.462)$, which were all $\mathrm{p}<.05$.

In session 2, the first day after work session, high fatigue after work showed a considerable trend toward significance to correlate with higher distraction ( $\mathrm{r}$ (19) $=.358, \mathrm{p}=.066)$. High workload was found to be associated with more effort ( $\mathrm{r}(19)$ $=.606)$, high stress $(\mathrm{r}(19)=.491)$ but lower distraction $(\mathrm{r}(19)=-.471)$ significantly, and high workload was also associated with shift type approaching conventional significance level $(\mathrm{p}=0.056)$. High stress was found to be associated with less rest and breaks $(\mathrm{r}(19)=-.454)$, all p's $<.05$.

In session 3 , the last day before work session, fatigue was significantly correlated with length of sleep $(\mathrm{r}(19)=.513)$, while the length of sleep was significant correlated with alertness $(\mathrm{r}(19)=.478)$, both $\mathrm{p}<.05$. Alertness was also correlated with sleep quality $(\mathrm{r}(19)=.533, \mathrm{p}<.01)$ and highly correlated with general health status $(\mathrm{r}(19)=.826, \mathrm{p}<.001)$. In addition, sleep quality was correlated with general health status $(\mathrm{r}(19)=.750, \mathrm{p}<.001)$ in this session.

In the session 4, the last day after work session, high fatigue after work was associated with high workload, more effort, and longer length of work, $r$ from .400 to .550 , all $\mathrm{p}<.05$. Fatigue also on the very borderline of significance correlated with 
shift type $(\mathrm{r}(19)=.374, \mathrm{p}=.057)$, stress $(\mathrm{r}(19)=.371, \mathrm{p}=.059)$, and distraction $(\mathrm{r}(19)$ $=.361, \mathrm{p}=.064)$.

Analyses for Each Day. The before-after work difference scores for fatigue scores were calculated using the post-work scores minus the pre-work scores. The positive score of change in fatigue shows the participants were more fatigued after work. The one-way ANOVA was also run to analyse the effect of shift type on change of fatigue.

In the first day, change in fatigue shows the direction heading towards significance to be associated with break time during work $(\mathrm{p}=0.10)$. Longer length of sleep was positively associated with a later time starting work $(\mathrm{r}(19)=.502)$ and negatively associated with a later time finishing work $(\mathrm{r}(19)=-.498)$, both $\mathrm{p}$ 's $<.05$. Good sleep quality was significant associated with less distraction $(\mathrm{r}(19)=-.458, \mathrm{p}<0.05)$. No significant effect of shift type found on this day.

In the last day, greater change in fatigue showed a significant positive correlation with more distraction during work $(\mathrm{r}(19)=.485, \mathrm{p}<.05)$. It was also close to the boundary of significance to correlate with the shorter length of sleep $(\mathrm{p}=.68)$, higher workload $(\mathrm{p}=.78)$, and worse quality of sleep $(\mathrm{p}=.85)$. A one-way analysis of variance showed that the effect of shift type was significant on fatigue changing, $\mathrm{F}(3,15)=5.27, \mathrm{p}=.011$. Post hoc LSD test indicated that the average change on fatigue in morning shift $(\mathrm{M}=3.29, \mathrm{~S} . \mathrm{D}=2.29)$ and night shift $(\mathrm{M}=1.00, \mathrm{~S} . \mathrm{D}=2.83)$ groups were significantly different from either afternoon shift $(M=6.33, \mathrm{~S} . \mathrm{D}=1.37)$ or early morning shift $(M=6.25, S . D=2.21)$ groups. These showed that the beforeafter fatigue for those who worked afternoon shift and early morning shift was change significantly greater than those who worked the morning shift and night shift. To be noticed that, there are only two participants in the night shift group on the last day thus the results about mean fatigue change of this group could be biased.

\subsection{Summary}

The present diary study aimed to examine the associations between fatigue, workload, working hours, and shift work in realistic situations, and also to explore the effects of other risk factors on fatigue mentioned in Study 1. It used the online diary to assess fatigue and fatigue-related risk factors before and after work, on the first day and the last day of a working week. The hypothesis for this study predicted that high workload, long working time, irregular shift time, and insufficient breaks would be associated with increased fatigue. It also predicted that reported fatigue would be higher at the end of the workday due to the workload effect. As expected, the effects of workload and working hours on fatigue were found in this study, with high workload or longer working hours leading to increased feelings of fatigue after work. Fatigue before work could be caused by commuting, poor quality or insufficient duration of sleep, while fatigue after work could result from workload, length of work, and shift type. The greater increased fatigue was found in the afternoon and early morning shift than in the normal morning shift. It was also found to be associated with less alertness and more distraction at work which would bring risk to work. Due to the limited sample size, the effects of insufficient breaks on fatigue were not found clearly in this study. Overall, this hypothesis was partially accepted. 


\section{Discussion}

This research investigated the causes of rail staff fatigue using qualitative data (Study 1) and a diary (Study 2). The findings from these two studies, using different methodologies, showed similar results. In both studies, fatigue was found to be due to a heavy workload, long working time, shift-work, and insufficient rest and sleep, which was in line with previous studies [3, 5, 61, 70]. In Study 1, mental and emotional job demands were mentioned to be one of the causes of fatigue, which was consistent with previous research [64, 71] that reported workload in the modern railway industry to impose more cognitive demands rather than physical demands. The effect of workload on rail staff fatigue was found in both studies and a high workload would further increase fatigue as previous study suggested [5]. It was found that staff members who regularly started work in the morning were less fatigued than those who took the irregular shift work, especially the late afternoon or early morning shift. Poor sleep quality, insufficient length of sleep resulted in greater fatigue feeling, which was in line with previous studies either in the general fatigue field [27] or in the occupational fatigue field [70]. In addition, fatigue cumulated and increased the end of the week, suggesting an effect of cumulative work fatigue on the outcomes during a working week. It was very similar to fatigue among seafarers, that the occupational fatigue increased day by day, and cumulated at work and on leave [72].

It was found that fatigue before work was mainly associated with sleep quality, length of sleep, and the time spent on commute, while fatigue after work was associated with the workload and shift type. The effect of sleep on fatigue have been studied in previous papers which report that sleep loss results in the subjective feeling of fatigue, resulting in increased negative emotion and impaired decision-making ([27, 29, 31, 32]. Meanwhile, sleep deprivation could be influenced by shift-work, resulting in fatigue at work [73]. Such effect of sleep was found in current research, additionally, the buffering effect of rest and breaks during work on fatigue as reported in Study 1. It was reported that insufficient rest and break lead to fatigue, as well as increased risks to safety, and vice versa. Participants suggested having more rest time or days allowed them to recover from fatigue. The length of breaks during work, however, was not clearly associated with change in fatigue in the diary study, which might be because of the poorly placed timing of rest during the shift. It was reported that the breaks during work were placed at the very beginning of the shift or nearly at the end of it. The arrangement of breaks needed to be more thoughtful, otherwise the buffering effect of it on fatigue was wasted.

As for time spent on commute, it reflected the time spend on the commute task. According to Cameron [20], time is one of the most relevant variables which is associated with fatigue. Overtime work was frequently mentioned to result in fatigue, and prolonged time of the work task usually came with high job demands and resulted in fatigue. The maximum working hours found in Study 2 was 12 hours and the engineer (i.e., fleet) and train driver were the main job role that worked over 10 hours. These two job types were indicated to be the high fatigue risk job in a large-scale study [5], and had been focused on in previous studies [3]. Although the result of the diary study showed the workload mainly resulted in fatigue rather than the length of work, the high workload and long working hours were associated with each other. 
The influences of working hours and job demands (i.e., workload) on fatigue were found and consistent with previous research [35].

As suggested by previous studies [44,70], shift work and its duration were contributed to fatigue and impaired worker's wellbeing. Participants in Study 1 described how the irregular hours of shift-work affected their work-life balance, and how difficult it was to recover from a series of night shifts when an early morning shift was scheduled immediately after. Then in Study 2, shift work, especially early morning shift work was found to result in greater increases in fatigue. Although it was also commented in Study 1 that recovering from opposed shifts was extremely difficult, the shift pattern and its effect was not observed in the diary study due to the limited sample size.

The influence of individual differences was mentioned in Study 1, that personal preference of time of day could help with coping with specific shift-work. Such personal preference of time of day could be explained by the clock circadian regulator. As reviewed earlier in this paper, some polymorphisms of this regulator have already been identified, such as diurnal preference, an intrinsic period, responses to sleep deprivation and night shifts [55, 57, 58, 59]. Van Dongen and Belenky [60] suggested that the selection of individuals with a specific diurnal preference (e.g., night preference) to take specific shifts, especially night shift of early morning shift, can help to improve productivity, reduce errors, and decrease incidents and accidents. Such selections, however, should be done judiciously within ethically and legally acceptable boundaries and avoid discriminating based on genetic information.

\subsection{Limitations}

In the present diary study (Study 2), only one working week per staff was analysed, which might not comprehensively reflect the complete shift patterns in each individual or a single job role. The aim of our research was to investigate the causes of fatigue among rail staff, and the current literature covering different types of job that all may be susceptible to fatigue. The nature of different job roles varied to the extent that a few job roles were in highly sedentary working conditions (e.g., train driver) or in on-call work status (e.g., engineer), while others were not. Indeed, the results show that the occupational fatigue of our participants was influenced by workload, length of work, and shift type, and the subjective measurement of workload and the recording of start/end of work time were fair among all staff, reducing confounding effects. It is also important to consider that; the online diary study is less controlled than laboratory experiments. While the online diary is an advanced method for assessing fatigue closely in the context of daily work life, reminder texts or emails are needed to ensure that participants fill in each diary on time.

\subsection{Implication for Future Research}

Anund et al. [2] suggested that the amount of related fatigue studies in the rail industry is very limited. This research, therefore, enhances the knowledge of the causes of rail staff fatigue by analysing qualitative data and conducting an online 
diary study. It had a closer look at the fatigue experience among rail staff and brought a more detailed blueprint picture of fatigue and its causes in the rail staff's real-life. Similar results were found from these two studies using different methodologies, that fatigue among rail staff was a result of heavy workload, long working hours, shiftwork, and insufficient rest and sleep. Besides, the qualitative data provide new angles for future study. In the future, the relationships between breaks, shift pattern, fatigue can be further studied, as well as the diurnal preference and strategies of sleep and rest between opposed shifts. Future research could investigate the timing of rest and breaks during work. This was frequently mentioned and complained about in Study 1 but was not assessed in Study 2 due to the limited sample. As part of the shift pattern, the record of duration and timing of breaks would be complex, and the required amount of data could be overwhelming. Therefore, to measure and analyse this factor, further data and a larger sample will be needed.

\section{Conclusion}

This research investigated the causes of fatigue among rail staff using qualitative data and diary. The findings from the two studies, using different methodologies, showed similar results that fatigue among rail staff was a result of heavy workload, long working hours, shift-work, and insufficient rest and sleep. Fatigue before work was mainly a result of sleep quality, length of sleep, and the time spent on commute, while fatigue after work resulted from the workload and shift type. Evidence has been provided that demonstrates how overtime work, specific shift pattern, insufficient rest day between opposed shifts, poor timing of breaks during work were also associated with fatigue, which could be further studied in the future.

Acknowledgments. The main content of this paper was part of JF's PhD thesis. JF would like to thank Prof. AS for his supervision and invaluable guidance in her $\mathrm{PhD}$ journey. Both authors are thankful to the anonymous reviewers for the comments which have helped in improving the article.

\section{References}

1. Phillips, R. O.: An assessment of studies of human fatigue in land and sea transport. TØI Report, https://www.toi.no/getfile.php/Publikasjoner/T\%C3\%98I\%20rapporter/2014/13542014/1354-2014-elektronisk.pdf (2014)

2. Anund, A., Fors, C., Kecklund, G., Leeuwen, W. V., Akerstedt, T.: Countermeasures for Fatigue in Transportation: A Review of Existing Methods for Drivers on Road, Rail, Sea and in Aviation. VTI Report 852A, https://www.researchgate.net/profile/Wessel_MA_Van_Leeuwen/publication/274703015_C ountermeasures for fatigue in transportation _a_review_of_existing_methods_for_drivers_on_road_rail_sea_and_in_aviation/links/552b 6c5a0cf29b22c9c1aa0f.pdf (2015)

3. Fan, J., Smith, A. P.: A preliminary review of fatigue among rail staff. Frontiers in psychology, 9, 634. (2018). 
4. Cebola, N., Golightly D., Wilson, J. R., Lowe, E.: Fatigue, anxiety, performance for on-call safety critical decision makers in rail maintenance: A diary study. In: Dadashi, N., Scott, A., Wilson, J.R., Mills, A. (eds.), Rail human factors: supporting reliability, safety and cost reduction, pp. 328--336. Taylor and Francis Group, Boca Raton (2013).

5. Fan, J., Smith A.P.: The Impact of Workload and Fatigue on Performance. In Longo L., Leva M. (eds.), Human Mental Workload: Models and Applications. Communications in Computer and Information Science, 726, pp. 90--105. Cham: Springer (2017) doi: 10.1007/978-3-319-61061-0_6

6. Craig, A., Cooper, R. E.: Symptoms of acute and chronic fatigue. In Handbook of Human Performance, 3, 289--339 (1992)

7. Cercarelli, L. R., Ryan, G. A.: Long distance driving behaviour of Western Australian drivers. In L.R. Hartley (ed.), Proceedings of the Second International Conference on Fatigue and Transportation: Engineering, enforcement and education solutions, pp. 35--45. Canning ridge, Australia: Promaco (1996)

8. Hirshkowitz, M.: Fatigue, sleepiness, and safety: Definitions, assessment, methodology. Sleep Medicine Clinics, 8(2), 183--189 (2013)

9. Gander, P. H., Merry, A., Millar, M. M., Weller, J.: Hours of work and fatigue-related error: a survey of New Zealand anaesthetists. Anaesthesia and intensive care, 28(2), 178--183 (2000)

10.Horne, J., Reyner, L.: Vehicle accidents related to sleep: a review. Occupational and environmental medicine, 56(5), 289-294 (1999)

11.Leonard, C., Fanning, N., Attwood, J., Buckley, M.: The effect of fatigue, sleep deprivation and onerous working hours on the physical and mental wellbeing of pre-registration house officers. Irish Journal of Medical Science, 167(1), 22 (1998).

12.Nicol, A. M., Botterill, J. S.: On-call work and health: a review. Environmental Health, 3(1), $15(2004)$

13.Bowler, N., Gibbon, W. H.: Fatigue and Its Contribution to Railway Incidents. British Rail Accident Investigation Branch (RAIB), https://www.rssb.co.uk/Library/risk-analysis-andsafety-reporting/2015-02-str-fatigue-contribution-to-railway-incidents.pdf (2015)

14.Kogi, K., Ohta, T.: Incidence of near accidental drowsing in locomotive driving during a period of rotation. Journal of Human Ergology, 4(1), 65--76 (1975). doi: $10.11183 /$ jhe1972.4.65

15.Ugajin, H.: Human factors approach to railway safety. Quarterly Report of RTRI, 40(1), 5--8 (1999). doi: 10.2219/rtriqr.40.5

16.British Rail Safety and Standards Board T059 Main Report: Guidelines for the Management and Reduction of Fatigue in Train Drivers, https://www.rssb.co.uk/research-developmentand-innovation/research-project-catalogue/t059 (2005)

17.British Rail Accident Investigation Branch.: Derailment of Two Locomotives at East Somerset Junction, http://www.raib.gov.uk/publications/investigation_reports/reports_2009/report282009.cfm (2008)

18.British Rail Accident Investigation Branch.: Uncontrolled Freight Train Run-back between Shap and Tebay, Cumbria, https://www.gov.uk/raib-reports/uncontrolled-freight-train-runback-between-shap-and-tebay-cumbria (2010)

19.Smith, A. P.: Adequate Crewing and Seafarers' Fatigue: The International Perspective. Centre for Occupational and Health Psychology, Cardiff University, http://www.itfseafarers.org/files/seealsodocs/3193/ITF\%20FATIGUE\%20REPORT\%20fina 1.pdf (2007)

20.Cameron, C.: A theory of fatigue. Ergonomics, 16(5), 633--648 (1973). doi: $10.1080 / 00140137308924554$

21.Smith, A. P., McNamara, R. L., Wellens, B. T.: Combined effects of occupational health hazards. Sudbury, Ontario: HSE Books (2004) 
22.Gates, A. J.: Variations in efficiency during the day, together with practise effects, sex differences, and correlations. Berkeley, CA: University of California Press (1916).

23.Huxtable, Z. L., White, M. H., McCartor, M. A.: A re-performance and re-interpretation of the Arai experiment in mental fatigue with three subjects. Psychological Monographs, 59(5), i (1945)

24.Davies, D. R., Parasuraman, R.: The psychology of vigilance. Academic Press (1982)

25.Gilbertova, S., Glivicky, V.: Monotony at work. Studia Psychologica, 9(4), 232--240 (1967)

26.Bergum, B. O., Lehr, D. J.: Vigilance performance as a function of interpolated rest. Journal of Applied Psychology, 46(6), 425 (1962)

27.Parkes, K. R.: Sleep patterns, shiftwork, and individual differences: A comparison of onshore and offshore control-room operators. Ergonomics, 37(5), 827--844 (1994)

28.Wadsworth, E. J., Allen, P. H., Wellens, B. T., McNamara, R. L., Smith, A. P.: Patterns of fatigue among seafarers during a tour of duty. American Journal of Industrial Medicine, 49(10), 836--844 (2006)

29.Wadsworth, E. J., Allen, P. H., McNamara, R. L., Smith, A. P.: Fatigue and health in a seafaring population. Occupational Medicine, 58(3), 198--204 (2008)

30.Thomas, M., Sing, H., Belenky, G., Holcomb, H., Mayberg, H., Dannals, R., ..., Welsh, A.: Neural basis of alertness and cognitive performance impairments during sleepiness. I. Effects of $24 \mathrm{~h}$ of sleep deprivation on waking human regional brain activity. Journal of Sleep Research, 9(4), 335--352 (2000)

31.Dinges, D. F., Pack, F., Williams, K., Gillen, K. A., Powell, J. W., Ott, G. E., ..., Pack, A. I.: Cumulative sleepiness, mood disturbance and psychomotor vigilance performance decrements during a week of sleep restricted to 4-5 hours per night. Sleep: Journal of Sleep Research \& Sleep Medicine, 20, 267--277 (1997)

32.Killgore, W. D., Balkin, T. J., Wesensten, N. J.: Impaired decision making following 49 hours of sleep deprivation. Journal of Sleep Research, 15(1), 7--13 (2006)

33.May, J. F., Baldwin, C. L.: Driver fatigue: The importance of identifying causal factors of fatigue when considering detection and countermeasure technologies. Transportation research part F: traffic psychology and behaviour, 12(3), 218--224 (2009)

34.Moos, R. H.: Psychosocial factors in the workplace. In: Fisher, S., Reason, J. (eds.), Handbook of life stress, pp. 193--209. Chichester, UK: Wiley (1988)

35.Hockey, G. R. J., Wiethoff, M.: Assessing patterns of adjustment to the demands of work. In: Puglisi-Allegra, S., Oliverio, A. (eds.), The psychobiology of stress. pp. 231--240. Dordrecht, Netherlands: Kluwer (1990)

36.Karasek Jr., R. A.: Job demands, job decision latitude, and mental strain: Implications for job redesign. Administrative Science Quarterly, 24(2), 285--308 (1979)

37.Marshall, N. L., Barnett, R. C., Sayer, A.: The changing workforce, job stress, and psychological distress. Journal of Occupational Health Psychology, 2(2), 99 (1997)

38.Van Yperen, N. W., Snijders, T. A.: A multilevel analysis of the demands-control model: Is stress at work determined by factors at the group level or the individual level? Journal of Occupational Health Psychology, 5(1), 182 (2000)

39.Van Yperen, N. W., Hagedoorn, M.: Do high job demands increase intrinsic motivation or fatigue or both? The role of job control and job social support. Academy of Management Journal, 46(3), 339--348 (2003)

40.Johnson, J. V., Hall, E. M.: Job strain, work place social support, and cardiovascular disease: A cross-sectional study of a random sample of the Swedish working population. American Journal of Public Health, 78(10), 1336--1342 (1988)

41.Karasek, R. A. Theorell, T.: Healthy work: stress, productivity and the reconstruction of working life, New York: Basic Books (1990)

42.Smith, L., Folkard, S., Tucker, P., Macdonald, I.: Work shift duration: A review comparing eight hour and 12 hour shift systems. Occupational and Environmental Medicine, 55(4), 217--229 (1998) 
43.Folkard, S., Tucker, P.: Shift work, safety and productivity. Occupational Medicine, 53(2), 95--101 (2003)

44.Duchon, J. C., Keran, C. M., Smith, T. J.: Extended workdays in an underground mine: A work performance analysis. Human Factors: The Journal of the Human Factors and Ergonomics Society, 36(2), 258--268 (1994)

45.Ferguson, S. A., Lamond, N., Kandelaars, K., Jay, S. M., Dawson, D.: The impact of short, irregular sleep opportunities at sea on the alertness of marine pilots working extended hours. Chronobiology International,25(2-3), 399--411 (2008)

46.Akerstedt, T.: Sleepiness at work: Effects of irregular work hours. In: Monk, T. (ed.), Sleep, sleepiness and performance, pp. 129--152. Oxford, England: John Wiley \& Sons (1991)

47.Kjellberg, A.: Sleep deprivation and some aspects of performance. Waking \& Sleeping, 1(2), 139--143 (1977)

48.Folkard, S., Lombardi, D. A., Tucker, P. T.: Shiftwork: Safety, sleepiness and sleep. Industrial Health, 43(1), 20--23 (2005)

49.Parkes, K. R.: Personality and coping as moderators of work stress processes: Models, methods and measures. Work \& Stress, 8(2), 110--129 (1994)

50.Cox, T., Ferguson, E.: Individual differences, stress and coping. Hoboken, New Jersey: Wiley (1991)

51.Laaksonen, M., Piha, K., Martikainen, P., Rahkonen, O., Lahelma, E.: Health-related behaviours and sickness absence from work. Occupational and Environmental Medicine, 66(12), 840--847 (2009)

52.Dawson, D., Reid, K.: Fatigue, alcohol and performance impairment. Nature, 388(6639), $235(1997)$

53.Wiese, J. G., Shlipak, M. G., Browner, W. S.: The alcohol hangover. Annals of Internal Medicine, 132, 897--902 (2000)

54.Yamazaki, S., Fukuhara, S., Suzukamo, Y., Morita, S., Okamura, T., Tanaka, T., Ueshima, H.: Lifestyle and work predictors of fatigue in Japanese manufacturing workers. Occupational Medicine, 57(4), 262--269 (2007)

55.Arendt, J.: Shift work: coping with the biological clock. Occupational Medicine, 60(1), 10$20(2010)$

56.Mark, G. M., Smith, A. P.: Stress models: A review and suggested new direction. In: Houdmont, J., Leka, S., (eds.) Occupational Health Psychology: European Perspectives on research, education and practice, pp.111--144. Nottingham University Press, Nottingham (2008)

57.Archer, S. N., Robilliard, D. L., Skene, D. J., Smits, M., Williams, A., Arendt, J., von Schantz, M.: A length polymorphism in the circadian clock gene Per3 is linked to delayed sleep phase syndrome and extreme diurnal preference. Sleep, 26(4), 413--415 (2003)

58.Von Schantz, M.: Phenotypic effects of genetic variability in human clock genes on circadian and sleep parameters. Journal of genetics, 87(5), 513--519 (2008)

59.Landgraf, D., Shostak, A., Oster, H.: Clock genes and sleep. Pflügers Archiv-European Journal of Physiology, 463(1), 3--14 (2012)

60.Van Dongen, H. P., Belenky, G.: Individual differences in vulnerability to sleep loss in the work environment. Industrial health, 47(5), 518-526 (2009)

61.Lal, S. K., Craig, A.: A critical review of the psychophysiology of driver fatigue. Biological Psychology, 55(3), 173--194 (2001)

62.British Office of Rail Regulation,: Managing Rail Staff Fatigue, http://orr.gov.uk/ data/assets/pdf file/0005/2867/managing rail fatigue.pdf (2012)

63.Frone, M. R., Tidwell, M. C. O.: The meaning and measurement of work fatigue: Development and evaluation of the Three-Dimensional Work Fatigue Inventory (3D-WFI). Journal of occupational health psychology, 20(3), 273 (2015)

64.Fan J., Smith A.P.: Mental Workload and Other Causes of Different Types of Fatigue in Rail Staff. In: Longo L., Leva M. (eds.) Human Mental Workload: Models and Applications. 
Communications in Computer and Information Science, 1012, pp. 147--159. Cham: Springer (2019)

65.Darwent, D., Dawson, D., Paterson, J. L., Roach, G. D., Ferguson, S. A.: Managing fatigue: it really is about sleep. Accident Analysis \& Prevention, 82, 20--26 (2015). doi: 10.1016/j.aap.2015.05.009

66.Prakash, S., Khapre, P., Laha, S. K., Saran, N.: Study to assess the level of stress and identification of significant stressors among the railway engine pilots. Indian Journal of Occupational \& Environmental Medicine. 15, 113--119 (2011). doi: 10.4103/00195278.93201

67.Härmä, M., Kavousi, A., Zaheri, S., Hamadani, A., Mirkazemi, R.: Assessment of the noise annoyance among subway train conductors in Tehran, Iran. Noise and Health. 16, 177--182 (2014). doi: 10.4103/1463-1741.134918

68.Smith, A. P., Smith, H.: Workload, fatigue and performance in the rail industry. In: Longo L., Leva M. (eds.) Human Mental Workload: Models and Applications. Communications in Computer and Information Science, 726, pp. 251--263. Cham: Springer (2017). doi: 10.1007/978-3-319-61061-0_17

69.Braun, V., Clarke, V.: Using thematic analysis in psychology. Qualitative research in psychology, 3(2), 77--101 (2006)

70.Dorrian, J., Baulk, S. D., Dawson, D.: Work hours, workload, sleep and fatigue in Australian Rail Industry employees. Applied Ergonomic. 42, 202--209 (2011). doi: 10.1016/j.apergo.2010.06.009

71.Young, M. S., Brookhuis, K. A., Wickens, C. D., Hancock, P. A.: State of science: mental workload in ergonomics. Ergonomics, 58, 1--17 (2015). doi: $10.1080 / 00140139.2014 .956151$

72.Bal, E., Arslan, O., Tavacioglu, L.: Prioritization of the causal factors of fatigue in seafarers and measurement of fatigue with the application of the Lactate Test. Safety science, 72, 46-54 (2015)

73.Cabonl, P., Lancelle, V., Mollard, R., Grau, J. Y., Blatter, C., Kaplan, M., et al. Sleep, fatigue and hours of work of French train drivers. In: Wilson, J. R., Mills, A., Clarke, T., Rajan, J., Dadashi, N. (eds.), Rail Human Factors around the World, pp. 783--791. London: CRC Press (2012) 